\title{
MedChemComm
}

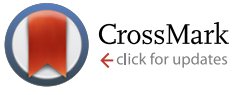

Cite this: Med. Chem. Commun., 2016, 7, 457

Received 30th October 2015 Accepted 23rd November 2015

DOI: $10.1039 / c 5 m d 00498$ e

www.rsc.org/medchemcomm

\section{Antiprotozoal activity of dehydroabietic acid derivatives against Leishmania donovani and Trypanosoma cruzi $\uparrow$}

\author{
Mikko Vahermo, ${ }^{a}$ Sara Krogerus, ${ }^{a}$ Abdelmajeed Nasereddin, ${ }^{\text {b }}$ Marcel Kaiser, ${ }^{c}$ \\ Reto Brun, ${ }^{c}$ Charles L. Jaffe, ${ }^{b}$ Jari Yli-Kauhaluoma ${ }^{a}$ and Vânia M. Moreira*a
}

\begin{abstract}
Derivatives of dehydroabietic acid bearing different amino acids scaffolds have potent antiprotozoal activity against Leishmania donovani and Trypanosoma cruzi, with good to high selectivity, and can therefore be regarded as good models for further development into new drugs to fight leishmaniasis and Chagas disease. Several of the tested compounds were able to kill parasites residing inside cells, with $\mathrm{IC}_{50}$ values ranging from 2.3 to $9 \mu \mathrm{M}$ (L. donovani) and 1.4 to $5.8 \mu \mathrm{M}$ (T. cruzi), reflecting their ability to fight these infections at the relevant stage responsible for disease. One of the compounds, bearing a 3-pyridyl-Dalanine side chain, was 1.5 -fold more potent against T. cruzi amastigotes residing in $L 6$ cells than the reference compound benznidazole.
\end{abstract}

\section{Introduction}

Protozoan diseases pose a significant health threat to populations world-wide. ${ }^{1-3}$ Among the most important protozoan diseases are those caused by trypanosomatids namely, leishmaniasis, Chagas disease and human African trypanosomiasis (HAT). Trypanosomatids are protozoan parasites which characteristically have a kinetoplast and a single flagellum. ${ }^{2,4}$ All members are parasitic and some have life-cycles including man as a secondary host, in which they cause disease. Chagas disease is caused by Trypanosoma cruzi, leishmaniasis by several Leishmania species and HAT is caused by Trypanosoma brucei. Triatomine bugs, sandflies and tsetse flies, transmit these diseases, respectively. It is estimated that 37 million people are infected with these parasites. ${ }^{5}$ Together with malaria and amoebiasis these diseases currently cause the death of approximately one million people per year. ${ }^{6}$

Leishmaniasis has three main forms. Visceral leishmaniasis which if left untreated, is fatal, mucocutaneous leishmaniasis that causes complete or partial destruction of mucous membranes of the nose, throat and mouth, and cutaneous

\footnotetext{
${ }^{a}$ Division of Pharmaceutical Chemistry and Technology, Faculty of Pharmacy, P. O. Box 56, Viikinkaari 5 E, FI-00014 University of Helsinki, Finland. E-mail: vania.moreira@helsinki.fi

${ }^{b}$ Department of Microbiology and Molecular Genetics, IMRIC, Hebrew UniversityHadassah Medical School, P. O. Box 12272, 9112102 Jerusalem, Israel ${ }^{c}$ Department of Medical Parasitology and Infection Biology, Swiss Tropical and Public Health Institute, Socinstrasse 57, 4051 Basel, Switzerland

$\dagger$ Electronic supplementary information (ESI) available: Characterization data for compounds 17 and 29 and in silico predicted properties for compounds 13-16, 19, 23-26 and 28. See DOI: 10.1039/c5md00498e
}

leishmaniasis, which causes skin lesions on exposed parts of the body that often heal slowly and leave behind scarring. ${ }^{7-9}$ Chagas disease, ${ }^{3,5,10}$ also known as American trypanosomiasis, is a two-stage disease with a chronic stage characterized by symptoms such as enlargement of the ventricles of the heart and enlarged esophagus or colon. Treatment of leishmaniasis has proven very challenging because of the complexity of the disease. Numerous species of Leishmania causing different syndromes have created a need for rapid methods of diagnosis and species identification to enable proper medical treatment. Until recently, antimonials such as sodium stibogluconate and meglumine antimoniate have been used for treatment. ${ }^{11}$ Nowadays better tolerated and more efficient drugs are available such as miltefosine, ${ }^{12}$ paromomycin, or liposomal amphotericin B as well as combinations of the three drugs. However, the efficacy of these treatments for leishmaniasis is threatened by environmental changes, drug resistance and immunosuppression, which largely contribute to disease outbreak and transmission. Nonetheless, chemotherapy and vector control still remain the mainstay for the management of leishmaniasis and Chagas disease as of today. ${ }^{13}$ Chemotherapy for Chagas disease includes benznidazole and nifurtimox. ${ }^{10}$ These drugs can be administered either separately or simultaneously and treatments cure up to $80 \%$ of the infections in the acute phase. However, as with leishmaniasis, drug efficacy is a problem because it decreases dramatically when treating the chronic phase of the disease, with only $5-20 \%$ of the patients successfully treated. ${ }^{14}$ It is therefore evident that there is an urgent need for the development of new drugs for these conditions with improved potency and a better side-effects profile. 
The abietanes are a class of naturally occurring tricyclic diterpenoids found in many terrestrial plant sources and bearing a diverse set of biological activities. ${ }^{15,16}$ Several naturally occurring and a few semi-synthetic abietanes have been reported to bear promising anti-leishmanial and trypanocidal properties, suggesting that this compound class is well suited for the development of novel agents for the treatment of diseases caused by trypanosomatids. For instance, the abietane quinone P-1 is active against both extracellular and intracellular forms of $L$. infantum, L. braziliensis and T. cruzi with $\mathrm{IC}_{50}$ values ranging from 14.2 to $24.5 \mu \mathrm{M}$ and was able to decrease to some extent the number of trypomastigotes in a mouse model of Chagas disease when administered i.p. at $1 \mathrm{mg} \mathrm{kg}{ }^{-1}$ per day for 5 consecutive days. ${ }^{17} \mathrm{~A}$ similar effect was observed after administration of (+)-fortunin $\mathrm{E}$ at $5 \mathrm{mg}$ $\mathrm{kg}^{-1}$ per day. ${ }^{18}$ The anti-leishmanial activity of a purified extract containing 12-methoxycarnosic acid isolated from Salvia repens Burch. ex Benth. was evaluated on $L$. donovani amastigotes and displayed a low $\mathrm{IC}_{50}$ value of $0.75 \mu \mathrm{M}$ and good selectivity. ${ }^{19}$ Other oxygenated abietane-type diterpenoids isolated from several plants including Dracocephalum komarovi Lipsky, Plectranthus barbatus Andrews, Salvia cilicica Boiss. \& Kotschy, Podocarpus lambertii Kotzsch ex Eichler,
Cryptomeria japonica (L.f.) D. Don and juniper (Juniperus procera Hochst. ex Endl.) berries have also been reported to have antiprotozoal properties. ${ }^{20-24}$ However, in some cases the testing was made only for extracellular parasitic forms whereas in others the compounds were either inactive or displayed limiting toxicity.

We have previously shown that the abietane-type diterpenoid dehydroabietic acid 1 (Fig. 1) is an effective agent against Staphylococcus aureus biofilms, with a good tolerability profile. ${ }^{25}$ In addition, we have recently designed and synthesized a set of amino acid-bearing derivatives of 1 , some of which with improved potency. ${ }^{26,27}$ We have found that these compounds have a fast-acting kinetics on the biofilms with a mode of action resembling that of many antimicrobial peptides (AMPs). It is widely known that AMPs interact with bacterial membranes as part of their mechanisms of action and that they display potent activities towards not only both Gram-positive and Gram-negative bacteria, but also against fungi, viruses, metazoans, as well as other parasites such as trypanosomatids, and even against cancer cells. ${ }^{28,29}$ Therefore, in this study, we set out to study the antiprotozoal properties of our set of dehydroabietic acid 1 derivatives against L. donovani and T. cruzi.<smiles>[R]C(=O)[C@]1(C)CCC[C@]2(C)c3ccc(C(C)C)cc3CC[C@]21C</smiles>

$1-4,6-13,18-31$<smiles>[R]C(=O)[C@]1(C)CCC[C@]2(C)c3ccc(C(C)C)cc3C([R2])C[C@@H]21</smiles>

$\mathrm{R}_{2}=\mathrm{O}$ $5,14,15$ $\mathrm{R}_{2}=\mathrm{NOH} \quad 16,17$

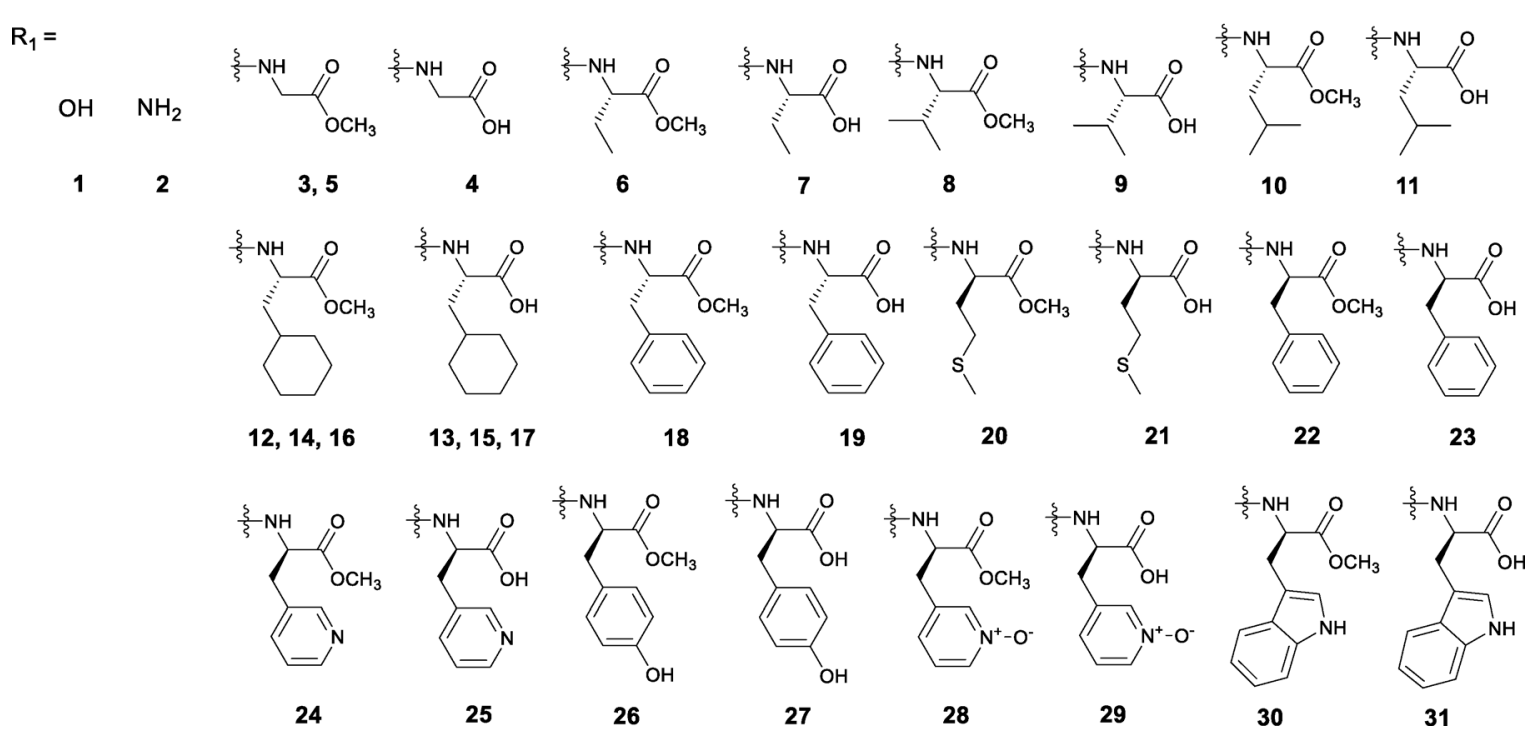

Fig. 1 The abietane-type compound collection screened in this study. 


\section{Results and Discussion}

An initial screening against $L$. donovani axenic amastigotes was made at a high concentration of $50 \mu \mathrm{M}$ for our compound collection depicted on Fig. 1. The collection comprised the parent compound 1 , its amide derivative 2 , and compounds built from 1 using carbodiimide coupling and base hydrolysis ${ }^{26,27}$ with L-amino acid derived side-chains, namely, compounds $\mathbf{3 - 1 9}$, and with D-amino acid side-chains (compounds 20-31). Two additional compounds 17 and 29 were synthesized to complete the set, following the same procedures. Compounds showing significant growth inhibition $(\geq 70 \%)$ at this concentration were assayed at $15 \mu \mathrm{M}$ and if significant activity was still retained, the $50 \%$ growth inhibition values $\left(\mathrm{IC}_{50}\right)$ on the axenic amastigotes were determined. Amphotericin B was used as a positive control. To rule out general cytotoxicity, the effects of the compounds on a human monocyte cell line (THP-1) were also evaluated with calculation of the corresponding selectivity index (SI). For the most potent compounds identified, activity against intracellular amastigotes was determined using infected THP-1 macrophages with calculation of the respective $\mathrm{IC}_{50}$ values. The results are depicted on Table 1 . We found that only a few of the compounds bearing small aliphatic side chains such as 7, 9, 11, 20 and 21 were active at $50 \mu \mathrm{M}$. Several compounds bearing aromatic side-chains were able to inhibit the growth of the parasites by more than $70 \%$ at this concentration, namely the phenylalanine, tyrosine and tryptophan derivatives 19, 22-24, 26-27 and 31. Remarkably, all but one (compound 12) of the compounds bearing the bulky, nonaromatic cyclohexyl-L-alanine side-chain were active at $50 \mu \mathrm{M}$. This activity was maintained at 15 and $5 \mu \mathrm{M}$ for all compounds (13-16) with the exception of 17. None of the compounds bearing the small aliphatic side-chains 7, 9, 11, 20 and 21 retained activity at lower concentrations suggesting that the size of the side-chain is relevant for the observed activity. Out of the compounds with aromatic side-chains, the L-phenylalanine 19, D-phenylalanine 23 and D-tyrosine 26 derivatives were still active at 15 and $5 \mu \mathrm{M}$. Compound 31 did not retain its activity at lower concentrations, suggesting that the bulkiness of the tryptophan group is not ideal for the activity and that a phenyl substituent is more suitable. Moreover, the inclusion of nitrogen in the phenyl ring in compound 24 does not favour the activity of the compounds nor does the presence of $\mathrm{N}$-oxides, as in compounds 28 and 29, which were among the least potent even at the highest

Table 1 Characterization of the anti-leishmanial activity of our compound collection

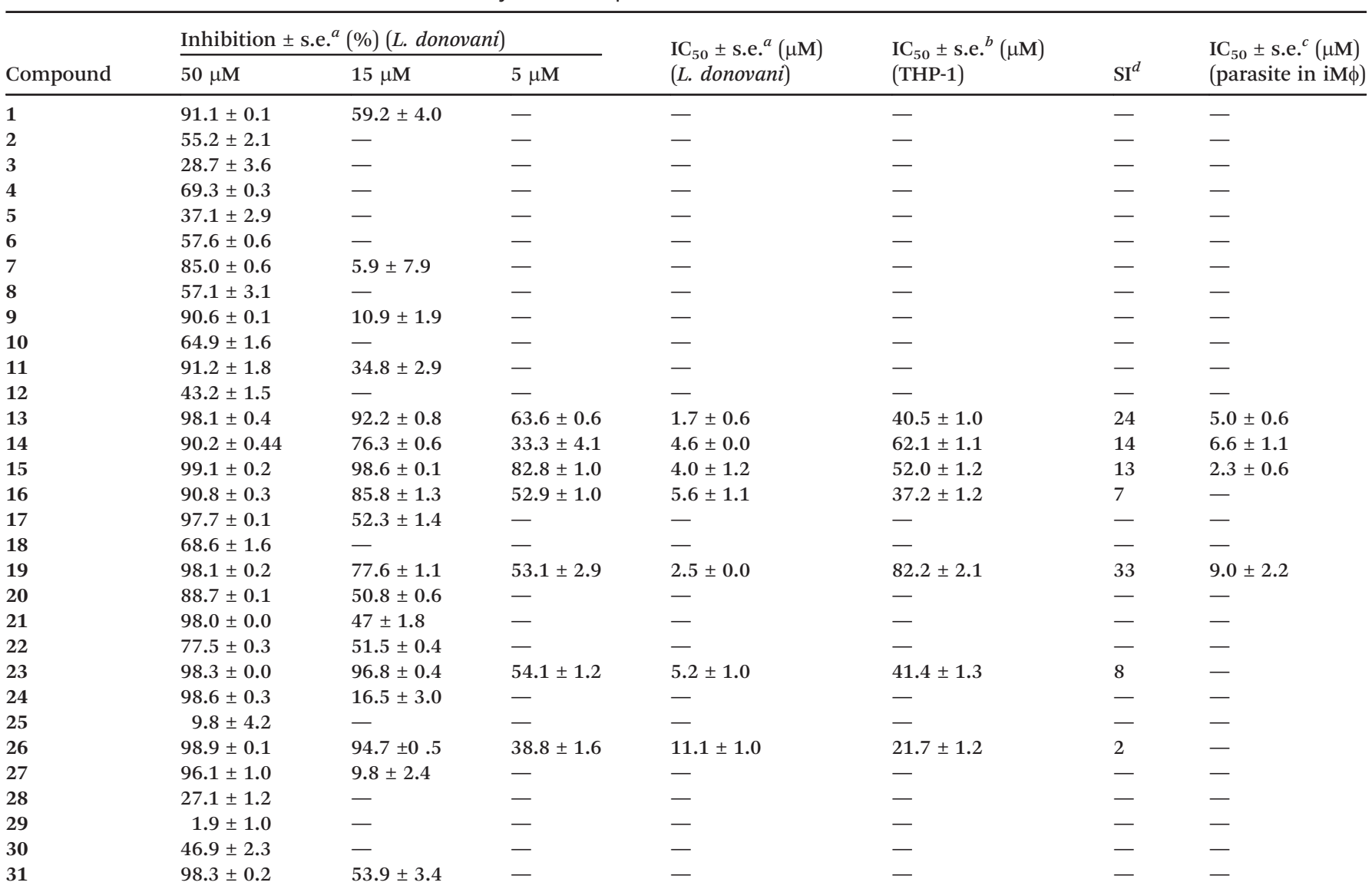

${ }^{a}$ L. donovani amastigotes. ${ }^{b}$ THP-1 cells. ${ }^{c}$ THP-1 cells infected with $L$. donovani. Amphotericin B was included as a positive control on each plate and gave $>90 \%$ inhibition of parasite growth at $1 \mu \mathrm{M} .{ }^{d} \mathrm{SI}=\mathrm{IC}_{50}$ (THP-1)/IC $\mathrm{I}_{50}$ (L. donovani). 
concentration tested. All active compounds in this group have a free carboxyl group except the tyrosine derivative $\mathbf{2 6}$. The best anti-leishmanial compounds were the cyclohexyl-Lalanine derivatives 13-16, the $\mathrm{L}^{-}$and $\mathrm{D}$-phenylalanine derivatives 19 and 23, respectively, and the D-tyrosine derivative 26. Their $\mathrm{IC}_{50}$ values against $L$. donovani amastigotes ranged from 1.7 to $11.1 \mu \mathrm{M}$. Compounds 13 and 19 displayed the best potency and selectivity indices above 20, which is considered "hit activity criterion for protozoa" when screening for new bioactive compounds. ${ }^{30}$ Compounds 14 and 15 displayed good selectivity $(10<\mathrm{SI}<20)$ whereas the toxicity of compound 23 was moderate and that of compound 26 poor (SI value of 2). Of note, compounds 13-15 and 19 were able to kill the parasites residing inside human macrophages with low $\mathrm{IC}_{50}$ values of 2.3 to $9 \mu \mathrm{M}$, which not only reveals their ability to permeate cell membranes but also their possible utility in fighting different stages of the parasite infection. Compounds 14 and $\mathbf{1 5}$ bear in common the presence of a carbonyl group at $\mathrm{C} 7$. The replacement of this group by an oxime in compound $\mathbf{1 6}$ resulted in higher toxicity.

We next tested the activity of the most promising derivatives 13-15, 19, 23, and the parent compound 1 against the amastigotes of the Tulahuen $\mathrm{C} 4$ strain of $T$. cruzi residing in rat skeletal muscle myoblasts (L6) cells. General cytotoxicity was also evaluated on the L6 cells. Benznidazole and podophyllotoxin were used as reference compounds. Compound 26 was also screened but found to have again limiting toxicity (SI of 1, data not shown). In addition, we included the test set of compounds 24, 25 and 28 having a modified phenyl-based side chain. The results are depicted on Table 2. All the selected compounds were active against $T$. cruzi and overall more potent than the parent compound 1. Among the most active compounds were again the cyclohexyl-L-alanine derivatives 14-16 with $\mathrm{IC}_{50}$ values between 4.2 and $5.8 \mu \mathrm{M}$. The phenylalanine derivatives 19 and 23 were less potent and selective against $T$. cruzi than against $L$. donovani. The best selectivity index was that of compound 15. Of note, compound 24 bearing a 3-pyridyl-D-alanine side chain was the

Table 2 Characterization of the trypanocidal activity of compounds 1 , $13-16,19,23-25$ and 28 on T. cruzi amastigotes

\begin{tabular}{llll}
\hline Compound & $\mathrm{IC}_{50} \pm \mathrm{SD}^{a}(\mu \mathrm{M})($ T. cruzi $)$ & $\mathrm{IC}_{50} \pm \mathrm{SD}^{a}(\mu \mathrm{M})(\mathrm{L} 6)$ & $\mathrm{SI}^{a}$ \\
\hline $\mathbf{1}$ & $101.3 \pm 46.1$ & $151 \pm 54.4$ & 1 \\
$\mathbf{1 3}$ & $22.8 \pm 6.4$ & $29.1 \pm 17.5$ & 1 \\
$\mathbf{1 4}$ & $4.2 \pm 1.6$ & $33.5 \pm 21.9$ & 8 \\
$\mathbf{1 5}$ & $3.9 \pm 1.4$ & $77.2 \pm 35.8$ & 20 \\
$\mathbf{1 6}$ & $5.8 \pm 2.5$ & $13.5 \pm 1.8$ & 2 \\
$\mathbf{1 9}$ & $33.1 \pm 7.7$ & $45.4 \pm 4.7$ & 1 \\
$\mathbf{2 3}$ & $27.7 \pm 8.3$ & $60.6 \pm 14.4$ & 2 \\
$\mathbf{2 4}$ & $1.4 \pm 0.3$ & $24.1 \pm 10.3$ & 17 \\
$\mathbf{2 5}$ & $83.1 \pm 16.5$ & $174.2 \pm 56.4$ & 2 \\
$\mathbf{2 8}$ & $32.7 \pm 6.4$ & $85.9 \pm 30.8$ & 3 \\
Bnz & $2.1 \pm 0.1$ & - & - \\
Podo & - & $0.02 \pm 0.01$ & -
\end{tabular}

${ }^{a} \mathrm{SI}=\mathrm{IC}_{50}(\mathrm{L6}) / \mathrm{IC}_{50}(T . \quad c r u z i), n=4 . \mathrm{Bnz}=$ benznidazole, Podo $=$ podophyllotoxin. most potent compound in this test set, with greater potency (1.5-fold) against T. cruzi amastigotes in L6 cells than the reference compound benznidazole, and a good selectivity index of 17. Its potency and selectivity is in sharp contrast with that of compounds 25, bearing the same side-chain but a deprotected carboxyl group, and the $N$-oxide derivative 28 .

Overall, we have found that the antiprotozoal activity of this class of compounds relies heavily on side chain size, aromaticity and compound amphipathicity. There seems to be an optimal balance of hydrophobicity, conferred by the cyclohexyl- or phenyl-based side-chain, and hydrophilicity/ hydrogen bonding ability, conferred by the presence of a side-chain nitrogen atom/carboxyl or hydroxyl group or by an additional carbonyl or oxime group at $\mathrm{C} 7$, that is required for the activity. This finding supports our hypothesis that the compounds may interfere with parasites membranes in a similar fashion to AMPs. However, whereas the activity and the usual accompanying toxicity of AMPs have been largely attributed to their cationicity, ${ }^{29}$ our compounds lack this character, as they have been built from hydrophobic, nonpolar L-, D- and unusual amino acid building blocks merged with the diterpenoid core. Further studies are currently underway to identify more specific modes of action of these compounds on the parasites.

of note, their easy preparation from starting materials widely abundant from natural sources represents an outstanding competitive advantage over conventional AMPs, whose practical applications are limited by their large size, susceptibility to enzymatic degradation, and high production costs. The compounds highlighted in this study namely, 13-16, 19, 23-26 and 28, all bear side chains based on either unusual or D-amino acids which may account for increased resistance against proteolysis. In silico predictions revealed that despite their low drug scores, these compounds are highly safe concerning possible mutagenic, tumourigenic, irritant and reproductive effects (Tables 1 and 2, ESI $\dagger$ ). Compound 24 has the best predicted drug score and complies with the Lipinski rule of $5 .{ }^{31}$

\section{Conclusion}

Our collection of dehydroabietic acid 1 derivatives bearing different amino acids scaffolds offers promising compounds for further development as antiprotozoal agents, useful for the treatment of diseases such as leishmaniasis and trypanosomiasis. In this study, we have identified several compounds that are potent antiprotozoal agents with good to high selectivity. Compounds 13-15 and 19 were particularly relevant for their ability to kill $L$. donovani inside infected macrophages and could therefore prove useful in fighting this infection at the relevant stage responsible for disease. Compound 15 was also very effective in killing T. cruzi amastigotes in L6 cells. Moreover, the activity of compound 24 against $T$. cruzi was remarkable, as it was more potent than the reference drug benznidazole, and showed good selectivity. Altogether, our 
work clearly highlights the value of natural compounds, such as the abietane-type diterpenoids, as innovative scaffolds for medicinal chemistry research in pursuit of novel and more effective treatments for neglected diseases.

\section{Experimental section}

\subsection{Chemistry}

All reagents were obtained from Sigma-Aldrich Co. $\beta$-Cyclohexyl-L-alanine methyl ester hydrochloride was obtained from Novabiochem (Läufelfingen, Switzerland). Dehydroabietic acid (90\% purity) was obtained from Pfaltz \& Bauer, USA. For thin layer chromatography (TLC) analysis, Kieselgel 60HF254/Kieselgel 60G was used (Merck). IR spectra were obtained using a Vertex 70 (Bruker Optics Inc., MA, USA) FTIR instrument. The FTIR measurements were made directly in solids with a horizontal attenuated total reflectance (ATR) accessory (MIRacle, Pike Technology Inc, WI, USA). The transmittance spectra were recorded at a $4 \mathrm{~cm}^{-1}$ resolution between 4000 and $600 \mathrm{~cm}^{-1}$ using the OPUS 5.5 software (Bruker Optics Inc., MA, USA). NMR spectra were obtained using a Varian Mercury Plus 300 spectrometer, in $\mathrm{CDCl}_{3}$ or DMSO- $d_{6}$, with tetramethylsilane (TMS) as the internal standard. The chemical shifts were reported in parts per million (ppm) and on the $\delta$ scale from TMS as an internal standard. The coupling constants $J$ are quoted in Hertz (Hz). LC-MS analyses for purity were executed with Waters Acquity® UPLC system (Waters, Milford MA, USA) attached to Acquity PDA detector and Waters Synapt G2 HDMS mass spectrometer (Waters, Milford MA, USA) via an ESI ion source. Samples were analyzed in positive, resolution ion mode. Mass range $(\mathrm{m} / \mathrm{z})$ was set from 100 to 600. Separation was performed in Acquity UPLC® BEH C18 column $(1.7 \mu \mathrm{m}$, $50 \mathrm{~mm} \times 2.1 \mathrm{~mm}$, Waters, Ireland) in $+40{ }^{\circ} \mathrm{C}$. The mobile phase consisted of $0.1 \%$ formic acid both in (A) $\mathrm{H}_{2} \mathrm{O}$ and (B) acetonitrile (Chromasolv® grade, Sigma-Aldrich, Steinheim, Germany). A linear gradient started at $95 \%$ of $\mathrm{A}$ and decreased to $10 \%$ in $6 \mathrm{~min}$. The flow rate of the mobile phase was $0.6 \mathrm{~mL} \min ^{-1}$, the injection volume was $2 \mu \mathrm{L}$ and tray temperature was set to $+10{ }^{\circ} \mathrm{C}$. Capillary voltage was set at $3.0 \mathrm{kV}$, sampling cone 30 and extraction cone 3.0, the source temperature $120{ }^{\circ} \mathrm{C}$ and desolvation temperature $360{ }^{\circ} \mathrm{C}$, cone and desolvation gas flow rate was set to $20 \mathrm{~L} \mathrm{~h}^{-1}$ and $800 \mathrm{~L} \mathrm{~h} \mathrm{~h}^{-1}$, respectively. Optical rotations were determined with an MCP 200 polarimeter (Anton Paar OptoTec GmbH, Germany) using a 1-mL capacity cell with $55-\mathrm{mm}$ path length. $[\alpha]_{\mathrm{D}}^{20}$ values are given in $\operatorname{deg} \mathrm{mL} \mathrm{g}^{-1} \mathrm{dm}^{-1}$. Melting points were measured on an Electrothermal IA9100 melting point apparatus and are uncorrected. The synthesis and characterization of all compounds but 17 and 29 has been previously reported by us. ${ }^{27}$

$N$-(7-Hydroximinoabiet-8,11,13-trien-18-oyl) cyclohexyl-Lalanine (17). Compound 17 was prepared from 16 (140 mg, $0.27 \mathrm{mmol}$ ) by dissolving it in THF : MeOH $1: 1(3.5 \mathrm{~mL})$ and adding a $4 \mathrm{M}$ aqueous solution of $\mathrm{NaOH}(3.1 \mathrm{~mL})$. The reaction mixture was stirred for $2.5 \mathrm{~h}$ at room temperature. It was then concentrated and water $(8 \mathrm{~mL})$ was added to the mixture followed by acidification with a $4 \mathrm{M}$ aqueous solution of $\mathrm{HCl}$. The acidic solution was extracted 3 times with ethyl acetate and the resulting organic phase was washed with brine, dried with anhydrous $\mathrm{Na}_{2} \mathrm{SO}_{4}$ and evaporated to dryness. Compound 17: off-white solid, mp $140{ }^{\circ} \mathrm{C}$ (dec), $121 \mathrm{mg}, 92 \%$. $[\alpha]_{\mathrm{D}}^{20}-53.69\left(c\right.$ 1.0, $\left.\mathrm{CHCl}_{3}\right) \cdot{ }^{1} \mathrm{H}$ NMR $\left(300 \mathrm{MHz}, \mathrm{CDCl}_{3}\right) \delta \mathrm{ppm}$ $1.13(\mathrm{~s}, 3 \mathrm{H}), 1.22$ (d, $J=4.0 \mathrm{~Hz}, 3 \mathrm{H}), 1.24(\mathrm{~d}, J=4.0 \mathrm{~Hz}, 3 \mathrm{H})$, $1.42(\mathrm{~s}, 3 \mathrm{H}), 2.29(\mathrm{~m}, 2 \mathrm{H}), 2.63(\mathrm{~m}, 1 \mathrm{H}), 2.83(\mathrm{~m}, 2 \mathrm{H}), 4.65$ $(\mathrm{m}, 1 \mathrm{H}), 6.15(\mathrm{~d}, J=7.7 \mathrm{~Hz}, 1 \mathrm{H}), 7.21(\mathrm{~s}, 2 \mathrm{H}), 7.57(\mathrm{~s}, 1 \mathrm{H}) .{ }^{13} \mathrm{C}$ NMR $\left(75 \mathrm{MHz}, \mathrm{CDCl}_{3}\right) \delta \mathrm{ppm} 16.6,18.5,23.2,23.8,24.0,24.0$, 26.1, 26.3, 26.6, 32.7, 33.7, 33.8, 34.5, 36.9, 37.3, 37.4, 39.7, 42.4, 46.6, 50.8, 122.2 (aromatic-C), 123.2 (aromatic-C), 128.4 (aromatic-C), 128.7 (aromatic-C), 146.8 (aromatic-C), 149.1 (aromatic-C), 155.8 (aromatic-C), 177.0 and 178.1 (COOH and CONH). FTIR (ATR) 3358, 1724, 1645, 1497, 1159, 1254, 821, $681 \mathrm{~cm}^{-1}$. Purity was determined as $>95 \%$ by UPLC-UV/PDAQTOF/MS; $\lambda 255 \mathrm{~nm}, R_{\mathrm{t}}$ : $4.66 \mathrm{~min}$. HRMS: calcd. for $\mathrm{C}_{29} \mathrm{H}_{43} \mathrm{~N}_{2} \mathrm{O}_{4} 483.3223[\mathrm{M}+\mathrm{H}]^{+}$, found 483.3223.

$\boldsymbol{N}$-(Abiet-8,11,13-trien-18-oyl) $\boldsymbol{H}$ - $\beta$-(3-pyridyl- $\boldsymbol{N}$-oxide)-D-alanine (29). Compound 28 (230 $\mathrm{mg}, 0.48 \mathrm{mmol})$ was dissolved in THF: $\mathrm{MeOH} 1: 1(6 \mathrm{~mL})$ and a $4 \mathrm{M}$ aqueous solution of $\mathrm{NaOH}(5.3 \mathrm{~mL})$ was added. The reaction mixture was stirred for $2 \mathrm{~h}$ at room temperature. Then it was concentrated and acidified with a $4 \mathrm{M}$ aqueous solution of $\mathrm{HCl}$. The resulting white solid was filtered, washed with water, and dried. Compound 29: white solid, mp $150{ }^{\circ} \mathrm{C}$ (dec), $200 \mathrm{mg}, 90 \%$. $[\alpha]_{\mathrm{D}}^{20}+27.26$ (c 1.0, DMSO). ${ }^{1} \mathrm{H}$ NMR $\left(300 \mathrm{MHz}, \mathrm{CDCl}_{3}\right) \delta \mathrm{ppm}$ $1.10(\mathrm{~s}, 3 \mathrm{H}), 1.12(\mathrm{~s}, 3 \mathrm{H}), 1.14(\mathrm{~s}, 3 \mathrm{H}), 1.16(\mathrm{~s}, 3 \mathrm{H}), 1.95$ (d, $J=$ $10.8 \mathrm{~Hz}, 1 \mathrm{H}), 2.24$ (d, $J=12.5 \mathrm{~Hz}, 1 \mathrm{H}), 2.69(\mathrm{~m}, 3 \mathrm{H}), 2.94(\mathrm{~m}$, 1H), 3.10 (dd, $J=4.7 \mathrm{~Hz}, 14.3 \mathrm{~Hz}, 1 \mathrm{H}), 4.55$ (m, 1H), 6.81 (d, $J$ $=1.6 \mathrm{~Hz}, 1 \mathrm{H}), 6.95(\mathrm{dd}, J=1.7 \mathrm{~Hz}, 8.1 \mathrm{~Hz}, 1 \mathrm{H}), 7.16(\mathrm{~m}, 2 \mathrm{H})$, $7.29(\mathrm{~m}, 1 \mathrm{H}), 7.76$ (d, $J=8.3 \mathrm{~Hz}, 1 \mathrm{H}), 8.07$ (m, 2H), 12.6 (bs, 1H). ${ }^{13} \mathrm{C}$ NMR (75 MHz, DMSO- $\left.d_{6}\right) \delta$ ppm 16.2, 18.3, 20.4, 23.9, 23.9, 24.9, 29.2, 32.7, 32.8, 36.3, 36.5, 37.4, 44.2, 46.3, 52.2, 123.4 (aromatic-C), 123.9 (aromatic-C), 125.6 (aromaticC), 125.9 (aromatic-C), 126.4 (aromatic-C), 134.4 (aromatic-C), 136.6 (aromatic-C), 137.6 (aromatic-C), 138.8 (aromatic-C), 144.9 (aromatic-C), 146.9 (aromatic-C), 172.7 and 177.6 (COOH and CONH). FTIR (ATR) 3332, 1733, 1635, 1534, 1208, $828,656 \mathrm{~cm}^{-1}$. Purity was determined as $>95 \%$ by UPLC-UV/ PDA-QTOF/MS; $\lambda 262 \mathrm{~nm}, R_{\mathrm{t}}: 3.52 \mathrm{~min}$. HRMS: calcd. for $\mathrm{C}_{26} \mathrm{H}_{39} \mathrm{NO}_{3} 465.2753[\mathrm{M}+\mathrm{H}]^{+}$, found 465.2753.

\subsection{Biology}

Anti-leishmanial activity. L. donovani (MHOM/SD/1962/1SCl2d) was used in all bioassays. Screening of the compounds for leishmanicidal activity using axenic amastigotes was carried out as previously described ${ }^{32}$ using the alamarBlue (AbD Serotec, Oxford, UK) viability assay similar to that reported for leishmanial promastigotes. Axenic amastigotes were grown at $37{ }^{\circ} \mathrm{C}$ in a $5 \% \mathrm{CO}_{2}$ incubator in complete RPMI 1640 containing $20 \%$ fetal calf serum, $\mathrm{pH} \mathrm{5.5.}{ }^{33}$ Compounds to be assayed were diluted in the complete amastigote medium containing $1 \%$ DMSO at twice the final 
concentration used in the assays, and were aliquoted in triplicate $(125 \mu \mathrm{L}$ per well) into 96-well flat-bottom plates (Nunc, Roskilde, Denmark). Initial screening was carried out $50 \mu \mathrm{M}$. $\mathrm{IC}_{50}$ was determined for the most active compounds using serial two-fold dilutions of the test compounds from 50 to 0.4 $\mu \mathrm{M}$. Amastigotes $\left(5.0 \times 10^{5}\right.$ cells per $\mathrm{mL} ; 125 \mu \mathrm{L}$ per well $)$ were added to each well and incubated for $24 \mathrm{~h}$ at $37^{\circ} \mathrm{C}$ in a $5 \% \mathrm{CO}_{2}$ incubator. The alamarBlue viability indicator was added $(25 \mu \mathrm{L}$ per well) and the plates incubated for an additional $24 \mathrm{~h}$ at which time the fluorescence $\left(\lambda_{\mathrm{ex}}=544 \mathrm{~nm} ; \lambda_{\mathrm{em}}\right.$ $=590 \mathrm{~nm}$ ) was measured in a microplate reader (Fluoroskan Ascent FL, Finland). Complete medium both with and without DMSO was used as negative controls $(0 \%$ inhibition of amastigote growth). Amphotericin B (Sigma-Aldrich, St. Louis MO), a drug used to treat visceral leishmaniasis, was included as a positive control on each plate and gave $>90 \%$ inhibition of parasite growth at $1 \mu \mathrm{M}$. Toxicity was measured using the alamarBlue viability indicator on human leukemia monocyte cells (THP-1, $6.4 \times 10^{4}$ cells per well) that were differentiated with retinoic acid as previously described. ${ }^{34} \mathrm{IC}_{50}$ was determined using serial two-fold dilutions of the test compounds in triplicate from 500 to $0.25 \mu \mathrm{M}$. Inhibition of intracellular amastigote growth in infected THP-1 cells $(5.0 \times$ $10^{5}$ cells per well) was carried out using transgenic Ld:pSSUint/LUC promastigotes that express luciferase. ${ }^{35}$ Amphotericin B $(1 \mu \mathrm{M})$ was included as a positive control on each plate. Complete medium both with and without DMSO was used as negative controls. Calculation of the $\mathrm{IC}_{50}$ 's and statistical analysis were carried out using GraphPad Prism version 6.0b (GraphPad Software, Inc. San Diego, CA).

Activity against Trypanosoma cruzi. Rat skeletal myoblasts (L6 cells) were seeded in 96-well microtiter plates at 2000 cells per well in $100 \mu \mathrm{L}$ RPMI 1640 medium with 10\% FBS and $2 \mathrm{mM}$ L-glutamine. After $24 \mathrm{~h}$ the medium was removed and replaced by fresh medium $(100 \mu \mathrm{L}$ per well) containing 5000 trypomastigote forms of $T$. cruzi Tulahuen strain C2C4 containing the $\beta$-galactosidase (Lac $\mathrm{Z}$ ) gene. ${ }^{36}$ After $48 \mathrm{~h}$, the medium was removed from the wells and replaced by $100 \mu \mathrm{L}$ fresh medium with or without a serial drug dilution of seven 3 -fold dilution steps covering a range from 90 to $0.123 \mu \mathrm{g}$ $\mathrm{mL}^{-1}$. After $96 \mathrm{~h}$ of incubation, the plates were inspected under an inverted microscope to assure growth of the controls and sterility. Then, the substrate CPRG/Nonidet $(50 \mu \mathrm{L})$ was added to all wells. A color reaction developed within 2-6 $\mathrm{h}$ and could be read photometrically at $540 \mathrm{~nm}$. Data were transferred into the graphic programme Softmax Pro (Molecular Devices), which calculated $\mathrm{IC}_{50}$ values. Benznidazole was the reference drug used.

Cytotoxicity against L6 cells. Assays were performed in 96well microtiter plates, each well containing $100 \mu \mathrm{L}$ of RPMI 1640 medium supplemented with $1 \%$ L-glutamine (200 mM) and $10 \%$ fetal bovine serum, and $4 \times 10^{4}$ L6 cells (a cell line derived from rat skeletal myoblasts). Serial drug dilutions of seven 3-fold dilution steps covering a range from 90 to 0.123 $\mu \mathrm{g} \mathrm{mL}^{-1}$ were prepared. After $72 \mathrm{~h}$ of incubation, the plates were inspected under an inverted microscope to assure growth of the controls and sterile conditions. Ten $\mu \mathrm{L}$ of alamar-Blue solution was then added to each well and the plates incubated for another $2 \mathrm{~h}$. Then the plates were read with a Spectramax Gemini XS microplate fluorometer using an excitation wavelength of $536 \mathrm{~nm}$ and an emission wavelength of $588 \mathrm{~nm}$. Data were analyzed using the microplate reader software Softmax Pro. Podophyllotoxin was the reference drug used.

\section{Acknowledgements}

The authors thank Dr. Nina Sipari from the Viikki Metabolomics Unit, University of Helsinki, for her kind assistance with the mass spectrometry analyses. Financial support for this work was provided by Academy of Finland (decisions 264020 and 265481) and Magnus Ehrnrooth Foundation (ME2012n44). CLJ holds the Michael and Penny Feiwel Chair in Dermatology.

\section{Notes and references}

1 P. Mäser, S. Wittlin, M. Rottman, T. Wenzler, M. Kaiser and R. Brun, Curr. Opin. Pharmacol., 2012, 12, 562-566.

2 K. Stuart, R. Brun, S. Croft, A. Fairlamb, R. E. Gürtler, J. McKerrow, S. Reed and R. Tarleton, J. Clin. Invest., 2008, 118, 1301-1310.

3 J. Clayton, Nature, 2010, 465, S3-S22.

4 A. Lopes, T. Souton-Padrón, F. A. Dias, M. T. Gomes, G. C. Rodrigues, L. Zimmermann, T. L. Alves e Silva and A. B. Vermelho, Open Parasitol. J., 2010, 4, 30-59.

5 M. B. Barrett, R. J. S. Burchmore, A. Stitch, J. O. Lazzari, A. C. Frasch, J. J. Cazzulo and S. Krishna, Lancet, 2003, 362, 1469-1480.

6 World Health Organization (WHO), Available from: http:// www.who.int/mediacentre/factsheets/fs387/en/.

7 B. L. Herwaldt, Lancet, 1999, 354, 1191-1199.

8 World Health Organization (WHO), Available from: http:// www.who.int/mediacentre/factsheets/fs375/en/.

9 S. L. Croft and G. H. Coombs, Trends Parasitol., 2003, 19, 502-508.

10 C. Bern, N. Engl. J. Med., 2015, 374, 456-466.

11 F. Frézard, C. Demicheli and R. R. Ribeiro, Molecules, 2009, 14, 2317-2336.

12 S. Sundar, T. K. Jha, C. P. Thakur, J. Engel, H. Sindermann, C. Fisher, K. Junge, A. Bryceson and J. Berman, N. Engl. J. Med., 2002, 347, 1739-1746.

13 J.-C. Dujardin, D. González-Paconowska, S. L. Croft, O. F. Olesen and G. F. Späth, Trends Parasitol., 2010, 26, 395-403.

14 M. A. Rajão, C. Furtado, C. L. Alves, D. G. Passos-Silva, M. B. Moura, B. L. Schamber-Reis, M. Kunrath-Lima, A. A. Zuma, J. P. Viera-da-Rocha, J. B. F. Garcia, I. C. Mendes, S. D. J. Pena, A. M. Macedo, G. R. Franco, N. C. Souza-Pinto, M. H. G. Medeiros, A. K. Cruz, M. C. M. Motta, S. M. R. Teixeira and C. R. Machado, Environ. Mol. Mutagen., 2014, 55, 309-321.

15 M. A. González, Nat. Prod. Rep., 2015, 32, 684-704. 
16 B. Zapata, M. Rojas, L. Betancur-Galvis, A. C. Mesa-Arango, D. Pérez-Guaita and M. A. González, Med. Chem. Commun., 2013, 4, 1239-1246.

17 I. Ramírez-Macías, C. Marín, H. Es-Samti, A. Fernández, J. J. Guardia, H. Zentar, A. Agil, R. Chahboun, E. Alvarez-Manzaneda and M. Sánchez-Moreno, Parasitol. Int., 2012, 61, 405-413.

18 F. Olmo, J. J. Guardia, C. Marín, I. Messouri, M. J. Morales, K. Urbanová, I. Chayboun, R. Chahboun, E. Alvarez-Manzaneda and M. Sánchez-Moreno, Eur. J. Med. Chem., 2015, 89, 683-690.

19 T. A. Mokoka, X. K. Peter, G. Fouche, N. Moodley, M. Adams, M. Hamburger, M. Kaiser, R. Brun, V. Maharaj and N. Koorbanally, S. Afr. J. Bot., 2014, 90, 93-95.

20 I. Ramírez-Macías, C. Marín, R. Chahboun, F. Olmo, I. Messouri, O. Huertas, M. J. Rosales, R. Gutierrez-Sánchez, E. Alvarez-Manzaneda and M. Sánchez-Moreno, Mem. Inst. Oswaldo Cruz, 2012, 107, 370-376.

21 N. Uchiyama, F. Kiuchi, M. Ito, G. Honda, Y. Takeda, O. K. Khodzhimatov and O. A. Ashurmetov, J. Nat. Prod., 2003, 66, 128-131.

22 R. A. Mothana, M. S. Al-Said, N. M. Al-Musayeib, A. A. El Gamal, S. M. Al-Massarani, A. J. Al-Rehaily, M. Abdulkader and L. Maes, Int. J. Mol. Sci., 2014, 15, 8360-8371.

23 N. Tan, M. Kaloga, O. A. Radtke, A. F. Kiderlen, S. Öksüz, A. Ulubelen and H. Kolodziej, Phytochemistry, 2002, 61, 881-884.

24 V. Samoylenko, D. C. Dunbar, M. A. Gafur, S. Khan, S. Ross, L. Mossa, F. El-Feraly, B. Tekwani, J. Bosselaers and I. Muhammad, Phytother. Res., 2008, 22, 1570-1576.
25 A. Fallarero, M. Skogman, J. Kujala, M. Rajaratnam, V. M. Moreira, J. Yli-Kauhaluoma and P. Vuorela, Int. J. Mol. Sci., 2013, 14, 12054-12072.

26 V. M. Moreira, M. Vahermo, A. Fallarero, J. Yli-Kauhaluoma and P. Vuorela, PCT/FI2015/050495, July 9th, 2015.

27 S. Manner, M. Vahermo, M. Sandberg, S. Krogerus, P. M. Vuorela, J. Yli-Kauhaluoma, A. Fallarero and V. M. Moreira, Eur. J. Med. Chem., 2015, 102, 68-79.

28 M. Zasloff, Nature, 2002, 415, 389-395.

29 B. S. McGwire and M. M. Kulkarni, Exp. Parasitol., 2010, 126, 397-405.

30 S. Nwaka and A. Hudson, Nat. Rev. Drug Discovery, 2006, 5, 941-955.

31 P. Lesson, Nature, 2012, 481, 455-456.

32 O. Shimony and C. L. Jaffe, J. Microbiol. Methods, 2008, 75, 196-200.

33 A. Debrabant, M. B. Joshi, P. F. P. Pimenta and D. M. Dwyer, Int. J. Parasitol., 2004, 34, 205-217.

34 C. Reichwald, O. Shimony, U. Dunkel, N. Sacerdoti-Sierra, C. L. Jaffe and C. J. Kunick, J. Med. Chem., 2008, 51, 659-659.

35 L. Keurulainen, A. Siiskonen, A. Nasereddin, D. Kopelyanskiy, N. Sacerdoti-Sierra, T. O. Leino, P. Tammela, J. Yli-Kauhaluoma, C. L. Jaffe and P. Kiuru, Bioorg. Med. Chem. Lett., 2015, 25, 1933-1937.

36 F. S. Buckner, C. L. Verlinde, A. C. La Flamme and W. C. van Voorhis, Antimicrob. Agents Chemother., 1996, 40, 2592-2597. 